\author{
Holly K. Craig \\ Julie A. Washington \\ University of Michigan, \\ Ann Arbor
}

\section{Grade-Related Changes in the Production of African American English}

This investigation examined grade as a source of systematic variation in the African American English (AAE) produced by students in preschool through fifth grades. Participants were 400 typically developing African American boys and girls residing in low- or middle-income homes in an urban-fringe community or midsize central city in the metropolitan Detroit area. Between preschoolers and kindergartners, and between first through fifth graders, there were no significant differences in the amounts of dialect produced during a picture description language elicitation context. However, there was a significant downward shift in dialect production at first grade. Students who evidenced dialect shifting outperformed their nonshifting peers on standardized tests of reading achievement and vocabulary breadth.

KEY WORDS: African American English, dialect, bidialectalism, code switching, language

$\mathrm{T}$ he purpose of this investigation was to contribute to current understanding of sources of systematic variation in child African American English (AAE) by examining the contribution of grade for students in elementary schools. AAE is a rule-governed and systematic variety of English that is spoken by many African American students when they begin formal schooling (Craig \& Washington, 2002). AAE is characterized by morphosyntactic and phonological features that are contrastive to their renderings in Standard American English (SAE), the primary variety of English that is used for classroom instruction, curriculum, and standardized testing instruments (Craig, Thompson, Washington, \& Potter, 2003; Hester, 1996; Labov, Baker, Bullock, Ross, \& Brown, 1998; Seymour, Bland-Stewart, \& Green, 1998; Smitherman, 1998; Washington \& Craig, 2002; Wolfram, 1994).

Considerable variability characterizes the extent to which African American preschool, kindergarten, and elementary grade students use contrastive AAE features (Thompson, Craig, \& Washington, in press; Washington \& Craig, 1994; Washington, Craig, \& Kushmaul, 1998). Washington et al. observed that a measure of dialect density, the ratio of contrastive AAE tokens to words, ranged from a minimum of .031 to a maximum of 196 for preschoolers and kindergartners. For students in later grades, Thompson et al. (2003) observed that the ratios for typically developing African American third graders also were highly variable, ranging from .015 to .270 . Although the latter investigation scored a more expansive set of features than the earlier work, it is noteworthy 
that at third grade some students produced as few as 1 dialectal variation for every approximately 67 words, whereas others produced as many as 1 feature for every approximately 4 words. These high levels of variability occurred in a context of considerable homogeneity within participant samples.

Variability in contrastive AAE feature production does not appear to be random. For preschoolers and kindergartners, spoken AAE has been shown to distribute systematically into clusters (Washington \& Craig, 1994; Washington et al., 1998). Washington et al. found that ratios of tokens to words distributed into naturally occurring and distinctive clusters of low, moderate, high, and very high AAE producing preschoolers and kindergartners. Interestingly, Craig and Washington (1994) found that the students using the low levels of AAE also produced low levels of complex syntax, and high AAE users produced more complex syntax, as well as more advanced semantic relationships (Craig \& Washington, 1995). The relationship between cluster membership and complex linguistic forms suggests that AAE-defined clusters may be associated with important language-related skills for young students. It has not yet been determined whether cluster membership is apparent in the discourse of students in the later grades or whether, if present, groups defined by dialect density bear important relationships to the language-based achievements of older students, such as reading.

There are a number of systematic sources of variation in child AAE feature production, including gender, socioeconomic status (SES), community, and discourse genre. In studies of students in early grades, boys produced more contrastive AAE features than girls (Craig \& Washington, 2002; Ratusnik \& Koenigsknecht, 1976; Washington \& Craig, 1994, 1998; Washington et al., 1998). Washington et al. observed that this gender-based frequency difference was specific to free play contexts and was not apparent in picture description samples of the same children. The authors noted that picture description removes the influences of toys, so that context differences may have reflected gender-based toy preferences apparent during the free play. In addition, in the early grades, children from low SES homes produced more AAE than their peers from middle SES backgrounds (Ratusnik \& Koenigsknecht, 1976; Washington \& Craig, 1998). Washington and Craig (1998) found that only tokens and not types of AAE are related to gender and SES variations in contrastive AAE features for preschoolers and kindergartners. In other work, older African American third graders evidenced no gender or SES differences during their picture descriptions (Thompson et al., in press), indicating that grade may affect the role of these variables for contrastive AAE feature production.
Community also influences dialect density for young students. Bountress (1983) found lower levels of production of selected contrastive AAE features by students in integrated schools than those of students in the same region who attended a school where $99 \%$ of the student body was African American. Further, the third graders participating in the Thompson et al. (in press) investigation were recruited from two communities, an urbanfringe community within metropolitan Detroit and a nearby midsize central city. Dialect density in picture description varied significantly related to community, with greater feature use during picture description by the urban-fringe students. The effect size for this relationship between AAE usage and community was small but warrants additional study to determine its importance in understanding child AAE.

Discourse genre is another important influence on the production of contrastive AAE features in the discourse of young students. Washington et al. (1998) found that preschoolers and kindergarteners produced more contrastive AAE features during semistructured picture descriptions than during spontaneous free play interactions. Unlike gender and SES influences on contrastive feature production, the differences in picture description compared to free play reflected increases not only in tokens, but also in AAE types. Thompson et al. (in press) also found that picture description elicited more contrastive AAE features by third graders than did other language production contexts. These latter comparisons were among picture description, oral reading of SAE text, and the production of a spontaneous writing sample. Most students produced contrastive AAE features in all contexts, and picture description elicited AAE features from all students.

Considered as a whole, the literature to date reveals the following:

1. Picture description is a particularly rich oral language elicitation context for examination of contrastive AAE features for students in preschool through the elementary grades.

2. Frequencies of contrastive AAE features vary widely within groups of young African American students.

3. Variability in contrastive AAE features derives from a number of systematic sources, and relates to gender, SES, community, and discourse genre.

Grade has been proposed as another potentially important source of systematic variation in AAE feature production, but its role is not well understood. The extant literature for child AAE is suggestive of a direct and inverse relationship between contrastive AAE feature production and grade. Accordingly, many African American students speak AAE at the time of school entry (Craig \& Washington, 2002), but a dialect shift 
toward SAE may occur as the child gains more exposure to the SAE of the classroom and curriculum (Adler, 1992; Battle, 1996; Fishman, 1991). Bountress (1983) observed that decreases in AAE features occurred between first, second, and third grade. Only four features were investigated in this study, however, and the decreases were feature-specific. Isaacs (1996) examined the grade-related productions of five nonstandard features by both African American and White third, fifth, and seventh graders. Similarly, she found that feature production decreased with increased grade. More features were produced by third graders than by fifth and seventh graders, and the fifth and seventh graders were not different from each other. Her data suggest a dialect shift, rather than a linear relationship between feature usage and grade. Like Isaacs, Craig et al. (2003) also found a sharp downward shift in AAE feature production. Their second graders produced significantly more AAE than did third, fourth, and fifth graders, and the AAE production of third through fifth graders did not materially differ from one another. Isaacs (1996) sampled feature production during picture description, whereas Craig et al. (2003) examined AAE production during oral reading.

Learning to dialect shift has considerable potential importance for academic achievement. Students who fail to achieve SAE competence may have difficulty processing curricular content presented in SAE (Taylor, Payne, \& Anderson, 1987; Wolfram \& Christian, 1989), or perhaps more fundamentally, learning to read (Craig \& Washington, in press). Unfortunately, the empirical investigation of a dialect shift by African American students that might support these proposals is very limited, and many important questions remain. Do these decreases characterize the development of language by AAE-speaking students, or just the operation of specific features? Does AAE production decrease in spoken discourse like it does in oral reading? How robust is this shift, and when does it occur? It is important to address these questions to improve our understanding of both child AAE and the congruence between AAE-speaking students and SAE classrooms.

In order to describe the AAE characterizing the language production of young African American students, and to examine systematic changes in AAE related to grade, the following questions were posed:

1. Are there statistically significant differences in the density of contrastive AAE feature production related to grade?

2. What are the $\mathrm{AAE}$ feature profiles by grade, and how do they compare across grades?

3. What is the relationship between dialect density and achievement?

\section{Method Participants}

The participants in this investigation were 400 typically developing African American boys $(n=178)$ and girls $(n=222)$ from low- $(n=150)$ and middle-SES $(n=$ 250 ) homes. They resided either in a midsize central city $(n=160)$ or in an urban-fringe community in the metropolitan Detroit area $(n=240)$. In the former, African American students represented $16 \%$ of the student body; in the latter, they represented $70 \%$ of the student body in the school district.

Gender and SES were allowed to vary. SES was determined by students' participation or nonparticipation in the federally funded free or reduced-price lunch program and scores were derived from the Hollingshead Four Factor Index of Social Status (Hollingshead, 1975). The Hollingshead Index, which was based on questionnaires that were completed by caregivers, assigned points for occupational status, level of schooling completed, marital status, and gender of the primary caregiver. Points were converted to a single score that corresponded with one of five levels. These levels varied based on whether the head of household was male or female. Based on Hollingshead's criteria, Levels 1 and 2 are always middle SES (MSES) and Levels 4 and 5 are always low SES (LSES). Level 3 varied based on whether there was a male or female head of household. For example, a male head of household who was assigned 30 points was placed into the MSES category whereas a female assigned 30 points was placed into the LSES category. Four students in third, fourth, and fifth grade were eliminated because background information was incomplete and their SES was unknown.

The recruitment process involved the distribution of consent forms to preschoolers, kindergartners, and first through fifth graders during 3 consecutive years. Students who returned the consent form were tested on a continuous enrollment basis until 300 typically developing elementary grade students and 100 typically developing preschoolers and kindergartners met the following criteria: (a) teacher and parent judgment as typically developing, (b) no history of referral for speech and language services or special education services, (c) performance within $2 S D$ s of the mean (standard score $[\mathrm{SS}] \geq 4$ ) on Triangles, a nonverbal culturefair assessment of a general cognitive skill found in the Kaufman Assessment Battery for Children (KABC; Kaufman \& Kaufman, 1983), and (d) no evidence of articulation problems. To create the participant sample of 400 children meeting these criteria, some students had to be eliminated from the investigation. Fifteen students in first through fourth grade were not included in this investigation because they were enrolled in 
special education services. Two students in fifth grade were eliminated because their Triangles scores did not meet the criterion of performance within $2 S D$ s of the mean.

In addition, Peabody Picture Vocabulary Test-Third Edition (PPVT-III; Dunn \& Dunn, 1997) standard scores were collected for all of the preschool through third grade students $(n=273)$. The PPVT-III scores were not dependent variables in this study but were available for the majority of the student participants. The PPVTIII assesses vocabulary breadth, estimates receptive vocabulary size, and is widely used as a measure of vocabulary achievement. All children from preschool through third grade had PPVT-III scores within $2 S D_{\mathrm{S}}$ of the mean ( $\mathrm{SS} \geq 71$ ). PPVT-III scores for 78 fourth and fifth graders were available. Those without PPVTIII scores $(n=49)$ were judged by their teachers to be performing similarly to their peers in the classroom. Seven students ( 3 preschoolers, 2 kindergartners, 1 first grader, and 1 fourth grader) were eliminated because their PPVT-III scores were $2 S D$ s or more below the mean of 100 .

Further, in order to interpret production of potential phonological types of AAE, it seemed important to identify students who had articulation difficulties. Articulation was assessed using the Percentage of Consonants Correct-Revised (PCC-R; Shriberg, Austin, Lewis, McSweeny, \& Wilson, 1997). The PCC-R was calculated by dividing the number of consonants articulated correctly by the number of consonants produced correctly plus incorrectly during picture description. Using this metric, only sound substitutions and deletions not related to dialectal variations were considered as errors. Based on Shriberg (1993), students were not penalized for common distortions such as lateralizing $/ \mathrm{s}, \mathrm{z}, \mathrm{J} /$. All of the participants achieved a PCC-R of $90 \%$ or greater.

In summary, these recruitment and selection procedures yielded a potential sample of 428 children. Twenty-four of these students were eliminated from the study because they had been enrolled in special education services or failed to meet the Triangles or PPVT-III cut-off scores, and 4 were removed because their SES was unknown. The remaining 400 students composed the participant sample for this investigation. The resulting distributions by grade are presented in Table 1.

\section{Data Collection}

Language samples were collected during a picture description task in which each child described three colored action pictures (Numbers 5, 7, and 24) from the Bracken Concept Development Program (Bracken,
Table 1. Numbers of participants by grade and community.

\begin{tabular}{lccc}
\hline \multicolumn{1}{c}{ Grade } & $\begin{array}{c}\text { Midsize } \\
\text { central city }\end{array}$ & $\begin{array}{c}\text { Urban-fringe } \\
\text { community }\end{array}$ & Total \\
\hline Preschool & 17 & 49 & 66 \\
Kindergarten & 11 & 28 & 39 \\
1st & 9 & 30 & 39 \\
2nd & 21 & 39 & 60 \\
3rd & 32 & 37 & 69 \\
4th & 36 & 27 & 63 \\
5th & 34 & 30 & 64 \\
\multicolumn{1}{c}{ Total } & 160 & 240 & 400 \\
\hline
\end{tabular}

1986). Pictures were presented in a random order during this untimed task. Students were given the prompt, "Tell me as much as you can about these pictures." If students simply labeled objects or actions, they were given an additional prompt: "Tell me what is happening in the picture." Both the child and the examiner wore head microphones and were audio-recorded.

Whereas AAE feature production was the focus of this investigation, it seemed important to analyze the potential effects of race of the examiner on the dialect density measure (DDM). Therefore, DDMs were examined to determine if there were differences in the language samples collected by an African American examiner versus those collected by a White examiner. The results of an independent $t$ test indicated no significant differences for total AAE DDM, $t(293)=1.2, p=.24$, by race of the examiner. Whereas some of the analyses probed for evidence of dialect shifting, comparable outcomes for DDM regardless of the race of the examiner indicated that any differences in dialect production levels were not attributable to this examiner characteristic.

\section{Scoring}

Following data collection, language samples were transcribed orthographically using the Coding for Human Analysis of Transcripts (CHAT) conventions of the Children's Data Exchange System (CHILDES; MacWhinney, 1994). Transcripts were coded for AAE morphosyntax, phonology, and combination (morphosyntax plus phonology) feature types (Craig et al., 2003; Washington \& Craig, 1994, 2002) (see the Appendix). Preschoolers' and kindergarteners' transcripts, however, were coded only for AAE morphosyntactic features, and comparisons across grades were based on the morphosyntactic feature system alone. These language samples were not coded for phonological and combination features because at this time in a child's development, it is difficult to determine whether phonological variations reflect dialectal features or motor immaturity. For example, consonant cluster reduction (e.g., "aroun(d)") is 
a major type of $\mathrm{AAE}$ phonological feature but also characterizes early developmental patterns of most students when the oral-motor system is immature.

A DDM was calculated in which AAE frequencies were divided by total number of words produced in the language sample. Craig, Washington, and ThompsonPorter (1998) introduced this ratio of features to words in order to control for potentially inherent relationships between longer sentences and increased opportunities for features to occur. For the elementary grade students in the current investigation, four separate DDMs were calculated for each language sample: morphosyntactic (MorDDM), phonological (PhonDDM), combination of morphosyntactic and phonological (CombDDM), and total AAE DDMs, which summed all features regardless of their morphosyntactic, phonological, or combination type. For example, in order to calculate PhonDDMs, tokens of phonological features were divided by the total number of words produced in a language sample.

In order to examine the relationship between $\mathrm{AAE}$ feature use and reading achievement, students' performances on national and state standardized reading achievement tests administered by the participating schools were obtained on a post hoc basis. Standardized scores were available for 199 (67\%) of the first through fifth graders. Standardized scores included the total reading score from the Iowa Tests of Basic Skills (Hoover, Dunbar, \& Frisbie, 2001); the reading score from the TerraNova (1997); the total reading score from the Metropolitan Achievement Tests (1993); and the mean of two reading subtests, Story and Informational, from the Michigan Educational Assessment Program (19992001), which is an achievement test required by the State of Michigan. Reading achievement scores were converted to $z$ scores in order to permit comparisons across the different achievement tests.

\section{Reliability}

Transcription reliabilities were established for all of the language samples. Approximately one third of each participant's language sample was retranscribed by an independent observer. Interobserver agreement was determined by dividing the number of agreements plus disagreements by the number of agreements. Agreements for transcription were $97 \%$ for morphemes and $93 \%$ for phonemes. Ten percent of the language samples were recoded for AAE features by an independent observer. Point-to-point coding agreements for morphosyntactic types and tokens were $99 \%$ and $85 \%$, respectively. Percentage agreement for phonology types was $98 \%$, and for tokens was $99 \%$. Interobserver agreements for combination types and tokens were $98 \%$ and $85 \%$, respectively.

\section{Results \\ Variations in DDMs by Grade}

DDMs were examined using univariate analysis of variance (ANOVA) relative to grade (seven levels), type of community (two levels), SES (two levels), and gender (two levels). Whereas only morphological features were calculated for preschoolers and kindergartners, MorDDMs were the basis for this first set of analyses. The MorDDMs were treated with the arcsine transformation to stabilize some of the variance inherent in proportional data. There were no significant interaction effects for the DDM relative to grade, community, SES, or gender, nor were there main effects for SES, $F(1,344)$ $=2.30, p=.13$, or gender, $F(1,344)=0.28, p=.60$. SES and gender were not examined further.

There were significant main effects for both community, $F(1,344)=28.4, p=.000$, and grade, $F(6,344)=$ $21.27, p=.000$. The mean MorDDMs for the urban-fringe community $(.069, S D=.052)$ were approximately twice that of the MorDDMs for the midsize central city (.036, $S D=.035$ ), as indicated in Figure 1. Although the main effect for community was significant, the effect size was very small $\left(\eta^{2}=.076\right)$.

Table 2 reports the mean DDMs by grade. MorDDMs ranged from .000 to .271 . Post hoc comparisons for grade

Figure 1. Mean morphosyntactic dialect density measures (MorDDMs) by grade and by community.

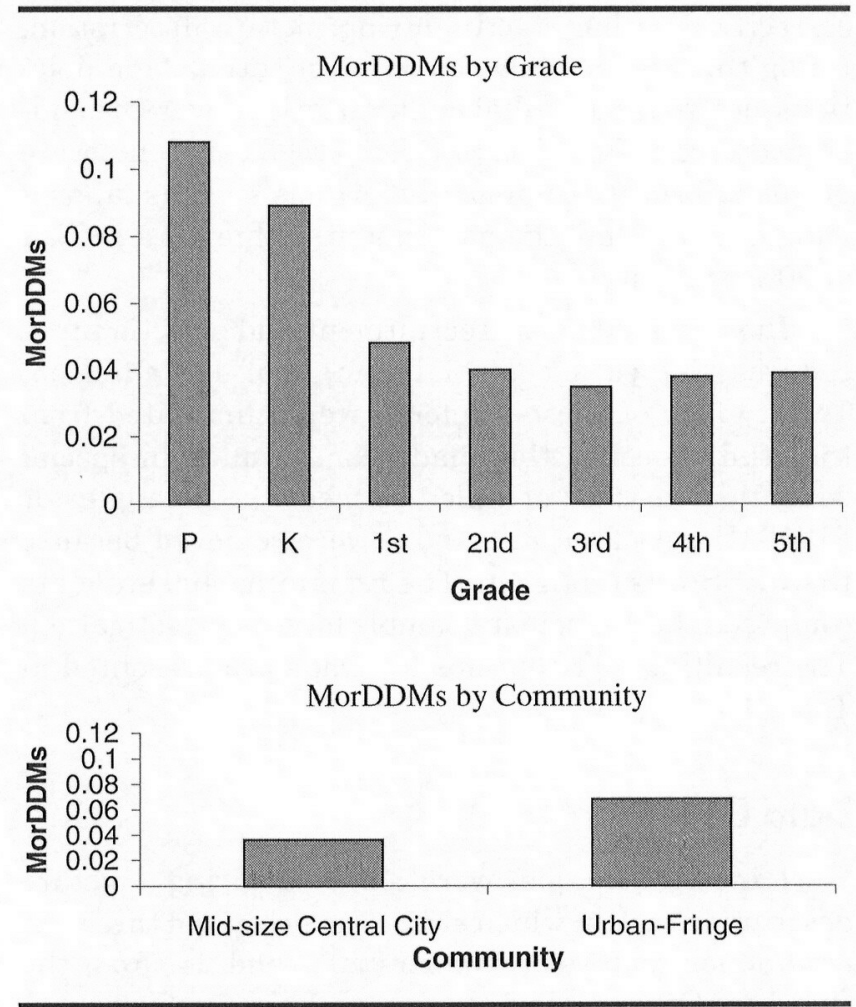


Table 2. Means and standard deviations for morphosyntactic dialect density measure (MorDDM), phonological (PhonDDM), and combination (CombDDM) by grade.

\begin{tabular}{|c|c|c|c|c|}
\hline Grade & MorDDM & PhonDDM & CombDDM & Totals \\
\hline \multicolumn{5}{|c|}{ Preschool $(n=66)$} \\
\hline$M$ & $.108^{1-5}$ & na & na & na \\
\hline$S D$ & .053 & & & \\
\hline \multicolumn{5}{|c|}{ Kindergarten $(n=39)$} \\
\hline$M$ & $.089^{6-10}$ & na & na & na \\
\hline$S D$ & .054 & & & \\
\hline \multicolumn{5}{|c|}{ Totals P-K $(n=105)$} \\
\hline$M$ & .101 & & & \\
\hline$S D$ & .054 & & & \\
\hline \multicolumn{5}{|l|}{$1 \mathrm{st}(n=39)$} \\
\hline$M$ & $.048^{1,6}$ & .074 & .006 & .129 \\
\hline$S D$ & .042 & .060 & .010 & .097 \\
\hline \multicolumn{5}{|l|}{$2 n d(n=60)$} \\
\hline$M$ & $.040^{2,7}$ & .057 & .003 & .100 \\
\hline$S D$ & .038 & .040 & .006 & .065 \\
\hline \multicolumn{5}{|l|}{$3 r d(n=69)$} \\
\hline$M$ & $.035^{3,8}$ & .055 & .003 & .094 \\
\hline$S D$ & .025 & .040 & .006 & .060 \\
\hline \multicolumn{5}{|l|}{4 th $(n=63)$} \\
\hline$M$ & $.038^{4,9}$ & .062 & .005 & .104 \\
\hline$S D$ & .031 & .045 & .006 & .069 \\
\hline \multicolumn{5}{|l|}{5 th $(n=64)$} \\
\hline M & $.0395,10$ & .061 & .004 & .104 \\
\hline$S D$ & .033 & .042 & .006 & .070 \\
\hline \multicolumn{5}{|c|}{ Totals 1st-5th $(n=295)$} \\
\hline M & $.039^{11}$ & $.061^{11}$ & .004 & .104 \\
\hline$S D$ & .033 & .045 & .007 & .071 \\
\hline
\end{tabular}

Between-group comparisons: ${ }^{1-10} p=.000$; within-group comparisons: ${ }^{11} p=.000$.

using Tukey's honestly significant difference procedure revealed that MorDDMs for preschoolers and kindergartners were not significantly different from each other. Further, the MorDDMs for the first through fifth graders were not significantly different from each other. In contrast, the MorDDMs for both the preschool and kindergarten students were significantly different from those for students in each of the first through fifth grades. Based on the grade differences reported above, it is not surprising that the 10 students who produced no morphosyntactic features were all first through fifth graders; none were preschoolers or kindergartners. In addition, the highest MorDDM of .271 was produced by a kindergartner. Considered together, MorDDMs were comparable prior to first grade, dropped significantly at first grade, and then remained relatively stable through the remainder of the elementary grades. The effect size for MorDDMs by grade was small $\left(\eta^{2}=.271\right)$. Effect size in the model estimated the impact for all of the grades together. The shift only at first grade and not across other grades may be responsible at least in part for the small effect size for the main effect of grade in the ANOVA model. Evaluating the impact of this grade effect somewhat differently, the shift at first grade represented a change from 1 morphological feature for every 10 words for preschoolers and kindergartners to only 1 morphological feature for every approximately 26 words for the first through fifth graders.

Table 2 also reports the DDMs for the phonological and combination feature systems, and for the total DDMs when all three subsystems are calculated together. Like the MorDDMs, the PhonDDMs and CombDDMs showed no significant grade effects for the first through fifth graders: PhonDDMs, $F(4,290)=1.24$, $p=.293$; CombDDMs, $F(4,290)=1.76, p=.138$. Across grades, the PhonDDMs were consistently greater than the MorDDMs. PhonDDMs were produced approximately one and one-half times more frequently than MorDDMs. This difference was statistically significant, pairwise $t(294)=9.36, p=.000$, and the effect size was moderate $(d=.55)$. The CombDDMs were consistently small across grades.

\section{Variations in Features by Grade}

The picture description context elicited a total of 6,316 instances of feature production across participants. Figure 2 displays the percentage of students producing specific features. The analysis examined only those features produced by $25 \%$ or more of the participants at that grade. This examination yielded two major findings. First, across grades, the number of different types of morphosyntactic features increased. In particular, more than $25 \%$ of the kindergartners produced the PRO and ING features, whereas the preschoolers did not (please refer to the Appendix for definitions and examples of these features). The ART feature was apparent for the third through fifth graders but not for those in the earlier grades. FSB was apparent for the second through fifth graders, and EIT for second, fourth, and fifth graders, but neither feature was apparent for those in the earlier grades. Using the $25 \%$ disbursement criterion, the first graders used three different morphosyntactic types, the second and third graders used six, and the fourth and fifth graders used eight different types. As a whole, the data indicate that the students were using a larger repertoire of morphosyntactic features as they progressed through the elementary grades. The development of a larger repertoire of morphosyntactic features contrasted sharply with the production of phonological features. For the phonological features, the same five types were produced at comparable levels across grades. 
Figure 2. Morphosyntactic and phonological types of features by grade. $\mathrm{COP}=$ zero copula/auxiliary; $\mathrm{ZAR}=$ zero article; $\mathrm{PST}$ = zero past tense; $\mathrm{ZPL}=$ zero plural; $\mathrm{SVA}=$ subject-verb agreement; $\mathrm{ZPR}=$ zero preposition; $\mathrm{PRO}=$ appositive pronoun; $\mathrm{ING}$ = zero -ing; $\mathrm{FSB}=$ fitna/sposeta/bouta; $A R T$ = indefinite article; EIT = existential it; $G=g$ dropping; $S T H=$ substitutions for $/ \theta /$ and $/ \partial / ; C C R=$ consonant cluster reduction; $\mathrm{PCR}=$ postvocalic consonant reduction; $\mathrm{SDL}=$ syllable deletion.
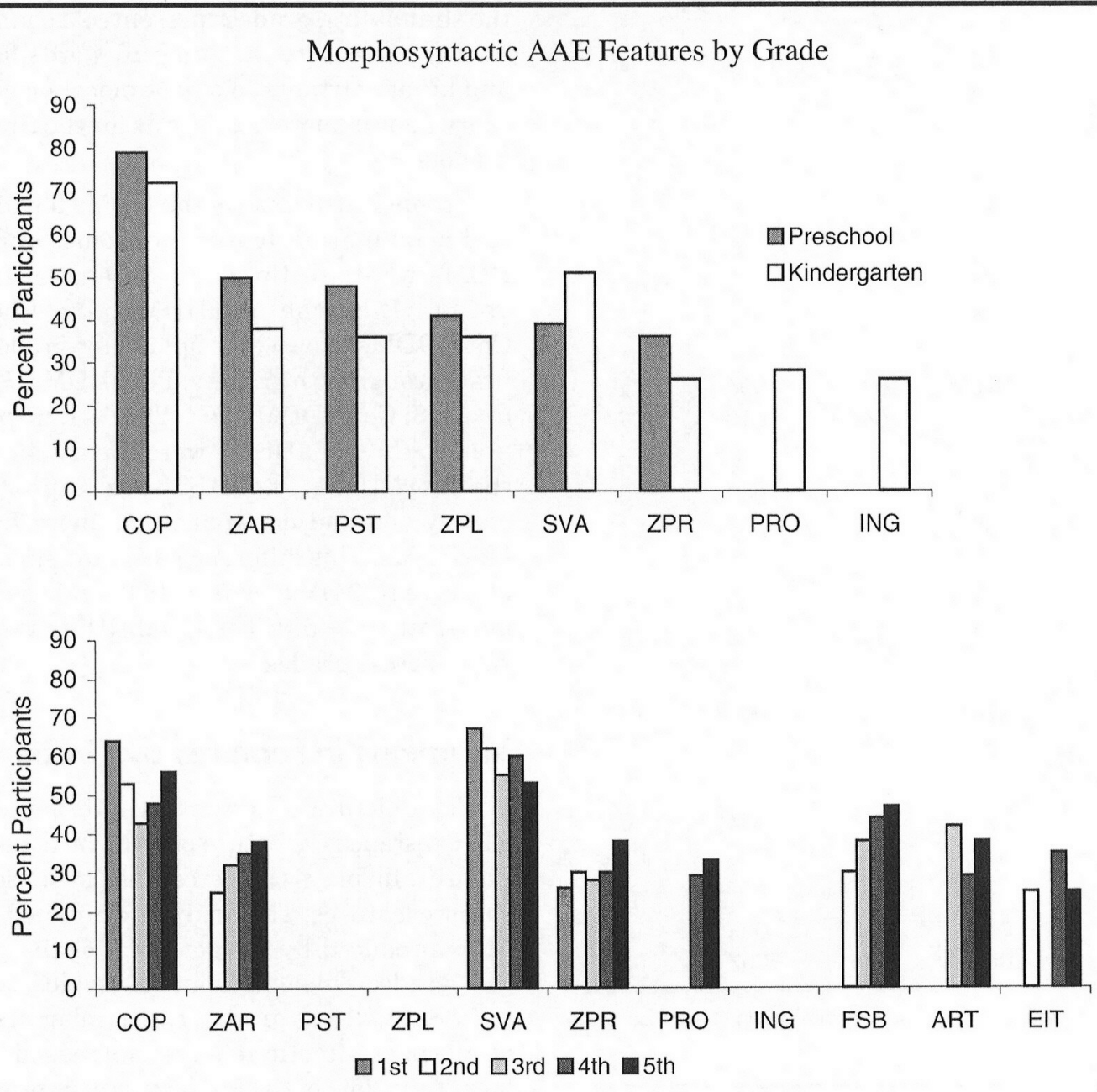

Phonological AAE Features by Grade

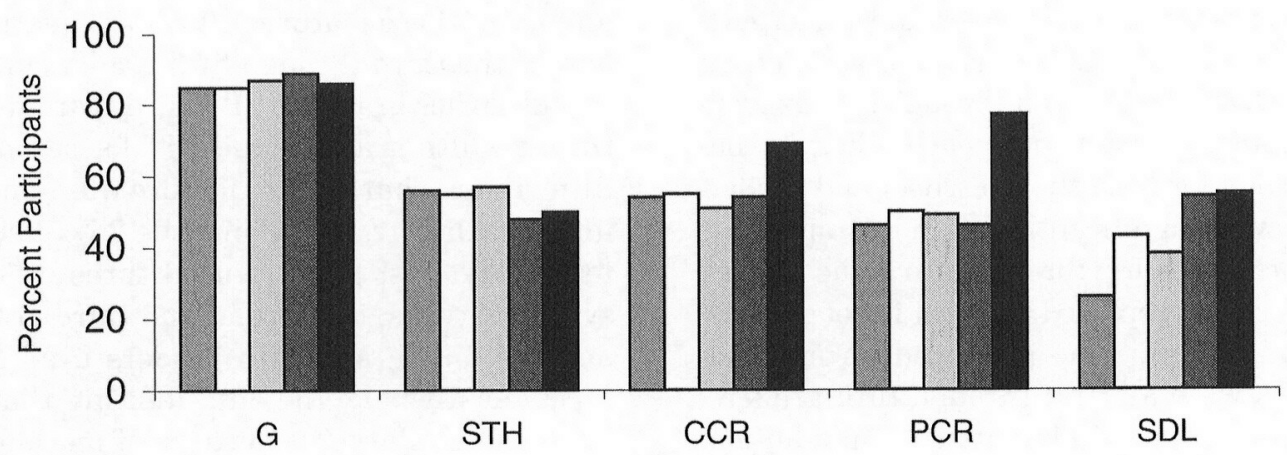

$\square$ 1st $\square$ 2nd $\square$ 3rd $\square$ 4th $\mathbf{E} 5$ th 
Second, once produced, most features remained a part of the student's repertoire of types. If the feature was used by $25 \%$ or more of the preschoolers and kindergartners, it was likely used by $25 \%$ or more of the first through fifth graders as well. In addition, the phonological features presented a relatively flat profile across grades, as did most of the morphosyntactic features. The PST, ZPL, and ING features were notable exceptions. They met the $25 \%$ participant criterion for the preschoolers and kindergartners, but did not do so for the first through fifth graders. By implication, these data indicate that although MorDDMs decreased, the repertoire of types increased across grades, and the phonological features remained the same.

\section{Interparticipant Variations in DDMs Within Preschool and Kindergarten, and First Through Fifth Grades}

The DDMs evidenced considerable variation across individual students regardless of grade. Interparticipant variability was explored further by applying a hierarchical cluster analysis to the MorDDM data, using the method of complete linkage. Figure 3 displays the distinct groups that were obtained with this analysis, and the specific values associated with each group are provided in Table 3 . The cluster analysis indicated that the variability in amounts of dialect appeared to distribute in systematic ways. Most students (50\%) in the preschool and kindergarten cohort clustered within a moderate range of MorDDMs. However, for the first through fifth graders, although a moderate cluster was still apparent, most students ( $68 \%$ ) clustered within the low range of MorDDMs. This shift in groups again was consistent with the main effects for grade, reported above. Overall, grade appeared to influence membership within specific clusters, and the size of the cluster. However, grade did not account for the basic finding that MorDDMs distributed into clusters. Specifically, the preschool and kindergarten data distributed into four distinct clusters, and so did the first through fifth grade data. The four clusters for the preschool and kindergarten and the first through fifth grade cohorts can be characterized in the same ways, in terms of low, moderate, high, and very high MorDDM groupings of students.

\section{Variations in DDMs Relative to Achievement}

Next, the distribution of the data into clusters was examined relative to achievement. The reading achievement $z$ scores of the largest MorDDM cluster, comprising first through fifth grade students who were using low levels of AAE, were compared to the first through fifth grade students who were using moderate to high levels of AAE. The four clusters were collapsed into two groups based on cluster size. The low AAE cluster, the largest cluster (68\% of the participants), was designated the dialect shifting group because their MorDDMs represented a marked downward shift from the levels of the preschoolers and kindergartners. The remaining students in the moderate, high, and very high clusters (32\% of the participants) were considered nonshifting.

The reading achievement scores of these two groups were significantly different, independent $t(197)=3.21$, $p=.002$, and the effect size was large $(d=.72)$. The mean $z$ score for the dialect shifting group was -.18 , whereas the mean $z$ score for the other students was -.62. It is noteworthy that the $z$ score for the nonshifting group was approximately six times worse than that for the students who were producing low levels of AAE (see Table 4). Together, these analyses indicated that most students in first through fifth grade were producing only low levels of AAE, and these students were performing significantly better on standardized tests of reading achievement than their peers who were producing higher levels of AAE.

The dialect shifting and nonshifting groups were examined further by comparing their PPVT-III scores that had been collected as part of the participant description measures (see Table 4). The PPVT-III standard scores of these two groups were significantly different, independent $t(244)=5.24, p=.000$, and the effect size was large $(d=1.0)$. Students in the dialect shifting group scored significantly higher (101.63) than those in the nonshifting group (92.75).

Figure 4 displays the percentage frequencies of students in each community who were dialect shifting and nonshifting; the distributions were significantly different, $\chi^{2}(1, N=295)=33.58, p=.000$. Students in the midsize central city appeared more likely $(86 \%)$ to be in the low MorDDM cluster, and thus considered to be dialect shifting, than were students in the urban-fringe community (54\%).

\section{$\overline{\text { Discussion }}$}

A major finding of this investigation was that grade was a source of systematic variation in the AAE produced by typically developing African American students in preschool through elementary grades. MorDDMs were not significantly different between preschool and kindergarten or between first through fifth grades. However, there was a sharp decline in MorDDMs between kindergarten and first grade. Students in first through fifth grades produced MorDDMs at a rate approximately $2^{1 / 2}$ times lower than that of the preschoolers 
Figure 3. Clusters for the preschoolers and kindergartners and for the first through fifth graders.

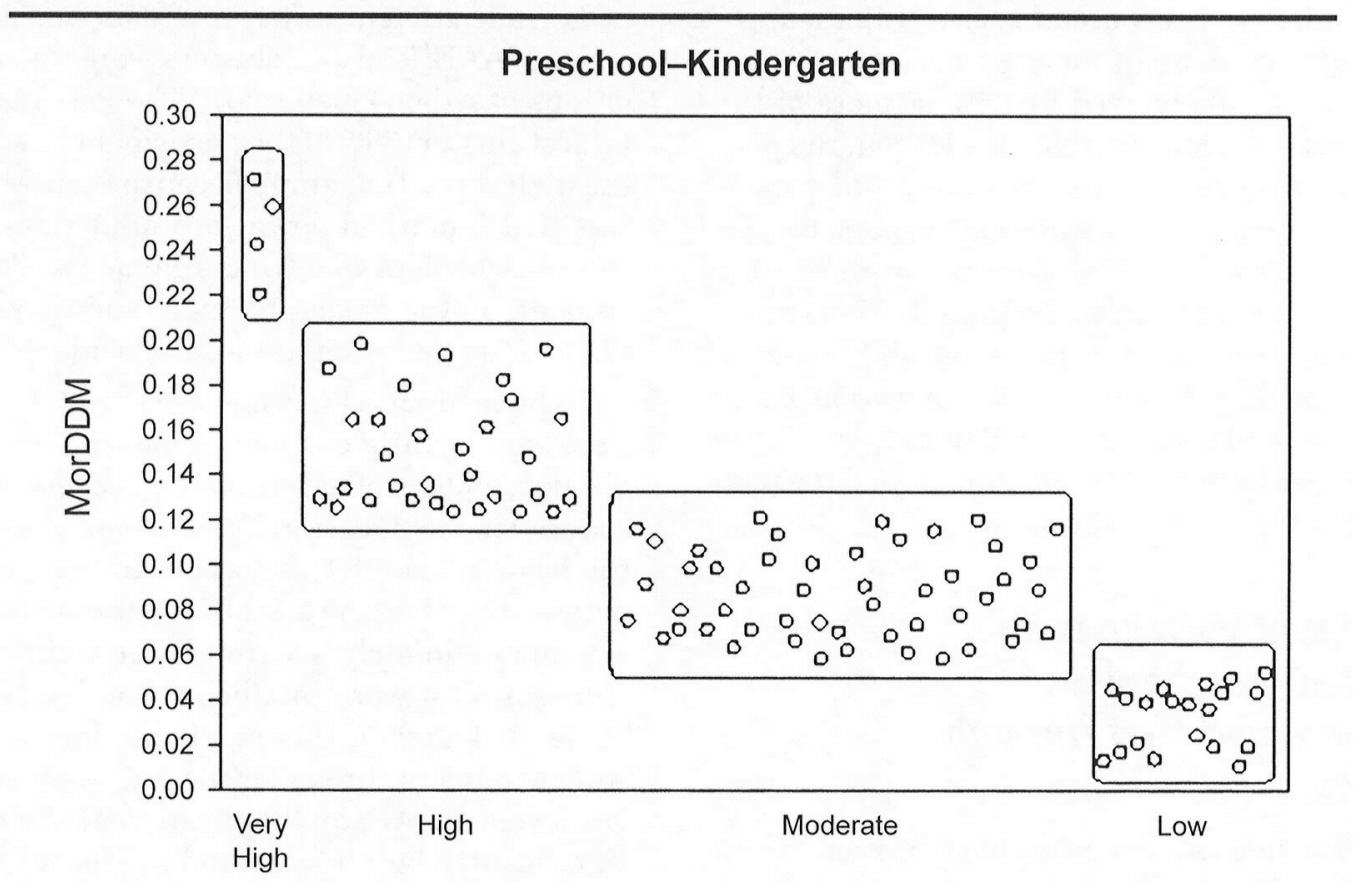

Grades 1-5

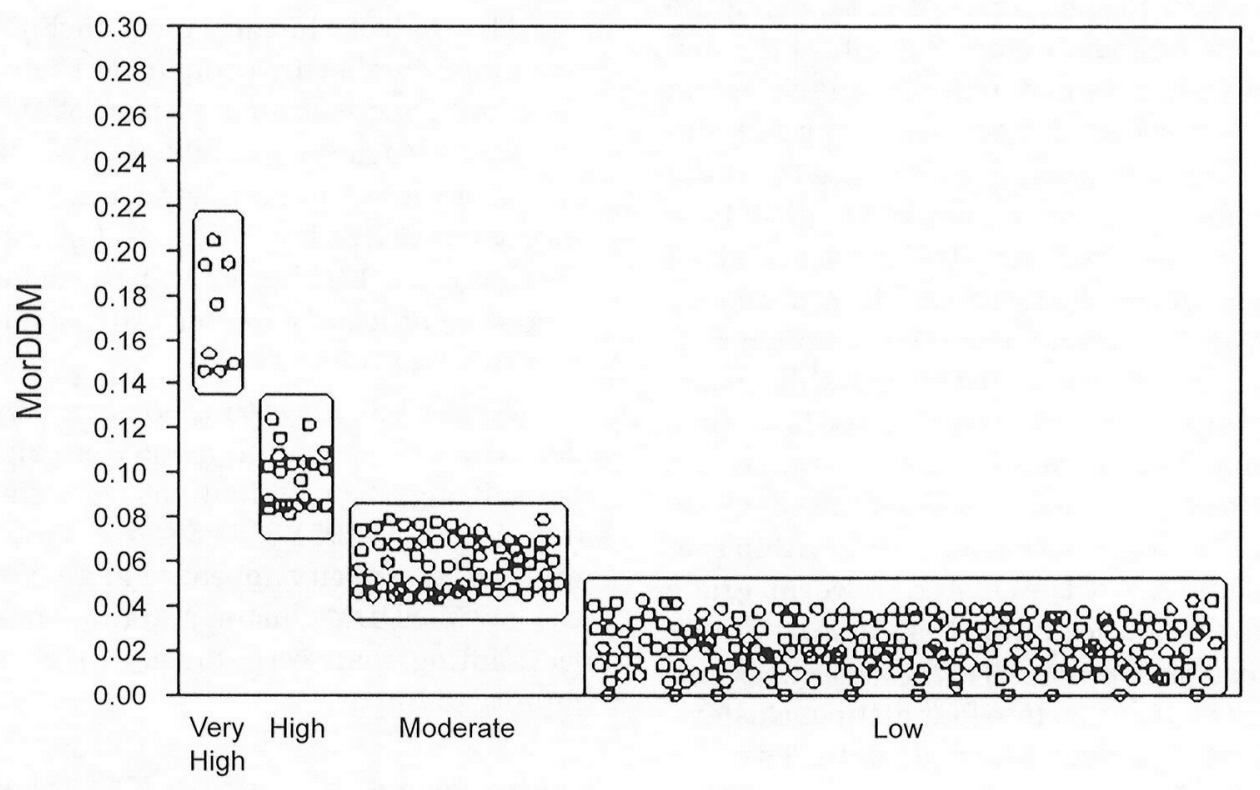

and kindergartners. The decrease in production of MorDDMs from approximately one morphosyntactic feature for every 10 words to only one morphosyntactic feature for every approximately 26 words was not characterized by a steady decrease across grades. In contrast, there was a sharp decrease in MorDDMs between kindergarten and first grade.

Previous research has characterized the decline in contrastive AAE feature production by students as a dialect shift (Adler, 1992; Battle, 1996; Fishman, 1991). It has not been clear in this research whether dialect shifting reflected a gradual linear change or a more precipitous drop. The current data indicate that the term dialect shifting is best characterized as a sharp decline that occurs in a relatively short timeframe. The current data also indicate that first grade is a critical time for the occurrence of dialect shifting. Approximately two thirds of the first through fifth graders were members of the lowest MorDDM cluster. Therefore, to the extent that cross-sectional data are valid representations of 
Table 3. The percentage frequencies and numbers of students in each cluster, and the minimum (Min) and maximum (Max) mean MorDDMs for preschoolers and kindergartners (P-K) and for first through fifth graders.

\begin{tabular}{|c|c|c|c|c|c|c|c|c|}
\hline & \multicolumn{4}{|c|}{$\mathrm{P}-\mathrm{K}$} & \multicolumn{4}{|c|}{$1 \mathrm{st}-5 \mathrm{th}$} \\
\hline & $\%$ & $N$ & Min & Max & $\%$ & $N$ & Min & Max \\
\hline Very high & 4 & 4 & .220 & .271 & 3 & 8 & .145 & .204 \\
\hline High & 29 & 31 & .123 & .198 & 7 & 21 & .081 & .123 \\
\hline Moderate & 48 & 50 & .058 & .121 & 22 & 65 & .043 & .078 \\
\hline Low & 19 & 20 & .011 & .052 & 68 & 201 & .000 & .042 \\
\hline
\end{tabular}

longitudinal trends, most first through fifth graders evidenced the dialect shifting pattern.

In the current investigation, language production was sampled during picture descriptions. The observed dialect shift in the current investigation, therefore, characterized spoken discourse. In other work, Craig et al. (2003) observed a sharp decline in phonological features between second and third grades for oral reading. That study examined oral reading, and the feature systems operated differently in that discourse genre than in the current picture descriptions. For reading, MorDDMs were low and flat across elementary grades. PhonDDMs predominated and showed a sharp decline between second and third grades. Considered together, therefore, it appears that the first shift substantially reduces the production of morphosyntactic features, and the second shift substantially reduces the production of phonological features. The findings of these two studies indicate that two periods for dialect shifting occur during the early elementary grades, one at first grade for spoken discourse and one at third grade for oral reading.

It is interesting that for both oral description and oral reading, dialect shifting occurs quite early in the process of the student's systematic exposure to the genre. Spoken dialect shifting during picture description at first grade is early in the process of participating in full days of SAE classrooms and the SAE curriculum. Dialect shifting for reading at third grade is relatively early in the process of reading acquisition, at the instructional

Table 4. The expected $(\mathrm{Ex})$ means and the obtained $(\mathrm{Ob})$ means and standard deviations of the achievement test $z$ scores and of the PPVT-III standard scores (SS) for the dialect shifting and nonshifting groups.

\begin{tabular}{lccccccc}
\hline & \multicolumn{3}{c}{ z scores } & & \multicolumn{3}{c}{ SS } \\
\cline { 2 - 4 } \cline { 6 - 8 } & Ex & Ob & SD & & Ex & Ob & $S D$ \\
\hline Dialect shifting & 0 & -.18 & .88 & & 100 & 101.63 & 11.95 \\
Nonshifting & 0 & -.62 & .90 & & 100 & 92.75 & 12.56 \\
\hline
\end{tabular}

Note. $\quad$ PPVT-III = Peabody Picture Vocabulary Test-Third Edition. juncture between emphasis on decoding and one on comprehension. Pragmatic models of child language acquisition are suggestive that linguistic form is dependent on discourse context, and that part of language acquisition is learning to match form to function (Bates \& MacWhinney, 1989; Craig, 1995; Ninio \& Snow, 1999). It is not surprising, therefore, that young African American students are sensitive to the SAE demands of classrooms and texts, are responsive to these formal exposures, and begin to adapt their linguistic forms to the SAE contexts in relatively short timeframes.

The change in the set of features produced in the later grades represents changes in morphosyntactic forms only; phonological features did not vary in type across grades. It is also the case that PST, ZPL, and ING types of morphosyntactic features decreased between kindergarten and first through fifth grades, so that at the later grades they no longer met the $25 \%$ criterion. These feature changes are difficult to interpret in the absence of longitudinal data but are suggestive that developmental factors may be contributing at least in part to the feature differences observed. Overall, the variations in specific features underscore the difficulty

Figure 4. Percentage frequencies of dialect shifting and nonshifting students by community.

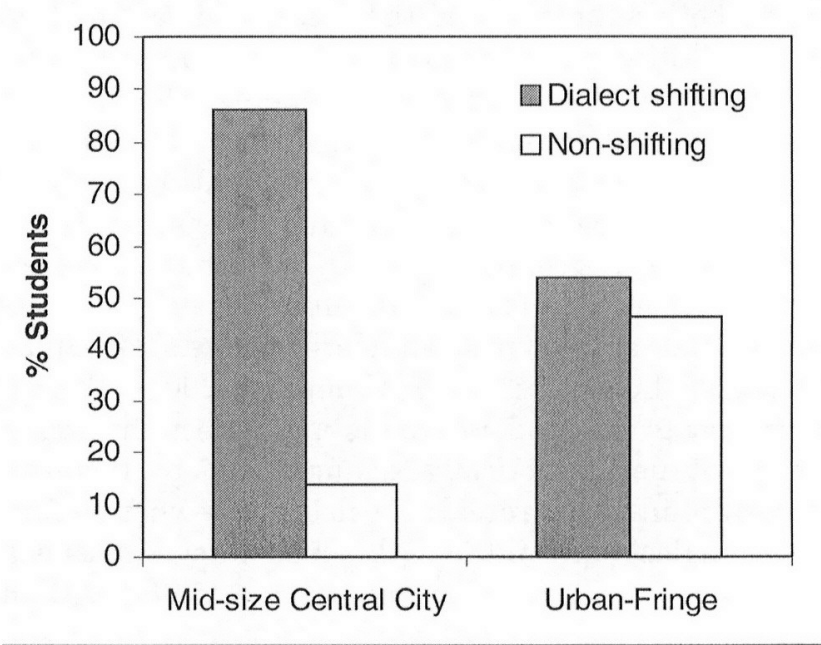


researchers face when trying to extrapolate student outcomes from the patterns of a limited subset. Research of this type is informative about the linguistic nature of the specific forms, but offers little guidance in understanding the complex interplay of dialect with schooling. Measures like DDM offer a fruitful alternative to feature-specific analyses of literacy acquisition.

Previous research has proposed that dialect shifting is a spontaneous response by African American students to immersion in the SAE of classrooms and curriculum. What if one does not dialect shift? Again assuming that the cross-sectional data reported here would mirror comparable longitudinal data, then two kinds of evidence in the current investigation are informative. First, it appears that students who continue to produce higher levels of AAE and who, by implication, are not dialect shifting, have more difficulty on standardized reading tests. Students who have reduced their AAE and, therefore, appear to be dialect shifting, have significantly better reading performances on a variety of nationally standardized tests than their nonshifting peers. The magnitude of the difference is quite large, an approximately six-fold difference. Interestingly, the students in this study who were dialect shifting performed close to the expected $z$-score mean. The group of nonshifting students performed at much lower levels. These data indicate that dialect shifting is advantageous for reading acquisition.

Second, the group of dialect shifting students performed significantly better than the nonshifting group on the PPVT-III. Although all students performed within the average range on the PPVT-III, the magnitude of the difference was again quite large, approximately onehalf the standard deviation between the two groups. Once more, the dialect shifting group approximated expected performances on this test. These outcomes provide strong evidence that dialect shifting is positive and is associated with measurably better reading and vocabulary achievement outcomes. The reading achievement test $\mathrm{z}$ scores and the vocabulary test standard scores both approximated the mean and revealed no "Black-White achievement gap" for the dialect shifting group. The AAE-speaking students who adapted their linguistic forms to the language contexts of the schools were outperforming their nonshifting peers. In contrast, the reading and vocabulary performances of the nonshifting group are consistent with the national data for African American students who perform in the low normal range on most standardized tests (Donahue, Finnegan, Lutkus, Allen, \& Campbell, 2001). The elementary grade student who is not dialect shifting is likely not the linguistically advanced student. It will be important in future research to determine whether failure to dialect shift in the early elementary grades is a symptom of pragmatic or linguistic weaknesses, and whether these limitations can be overcome.
Who dialect shifts? There is some evidence in this study that it is the students who are the most linguistically advanced. First, the MorDDMs, a measure of tokens, decreased across grades. This occurred in conjunction with a steady increase in types. Knowing more dialect features likely results from knowing more about language in general and is evidence of greater linguistic knowledge. Advancing grade is associated, therefore, both with dialect shifting and with larger feature sets. A second source of evidence to support this hypothesis derives from the PPVT-III scores. Higher PPVT-III scores presumably reflect greater vocabulary knowledge. Thus, the higher PPVT-III scores of the dialect shifters are consistent with the interpretation that the dialect shifters are the more linguistically advanced students. Although it is not possible to determine a causal relationship in this investigation, intuitively it seems possible that the more linguistically advanced students are the ones who also are pragmatically sensitive and able to accomplish dialect shifting spontaneously from exposure to SAE classrooms.

Students residing in the midsize central city were more likely to be in the low MorDDM cluster, and thus considered to be dialect shifting, than the students in the urban-fringe community. The student body in the midsize central city comprised fewer African American students than the urban-fringe community. Students in the midsize central city were more likely to experience $\mathrm{SAE}$ in their everyday interactions than the students in the urban-fringe community, and this exposure likely had an impact on their readiness to dialect shift at first grade when daily and systematic exposure to SAE was provided in their classrooms. This interpretation requires longitudinal study for confirmation, but the finding of main effects for community in this data set lends support to this interpretation.

In conclusion, this investigation revealed graderelated changes in AAE production best characterized as a sharp decrease in the students' use of morphosyntactic dialect features at first grade. Dialect shifting related to reading and vocabulary outcomes in important ways. Students who were strong linguistically and resided in more integrated communities had an advantage in making this shift. Although these findings require considerable additional probing, they offer new information about the interface between being an AAEspeaking student and reading achievement.

\section{Acknowledgments}

This work was supported by Grant R305T990368 from the U.S. Department of Education, Office of Educational Research and Improvement, and by Grant 1 R01 DC04273-01 from National Institute on Deafness and Other Communication Disorders. We gratefully acknowledge the cooperation of 
the students, families, and school personnel who participated in this study. In addition, we thank Connie A. Thompson for helpful comments throughout the preparation of this article.

\section{References}

Adler, S. (1992). Multicultural communication skills in the classroom. Boston: Allyn \& Bacon.

Bates, E., \& MacWhinney, B. (1989). Functionalism and the competition model. In B. MacWhinney \& E. Bates (Eds.), The crosslinguistic study of sentence processing (pp. 3-73). New York: Cambridge University Press.

Battle, D. E. (1996). Language learning and use by African American children. Topics in Language Disorders, 16, $22-37$

Bountress, N. G. (1983). Effect of segregated and integrated educational settings upon selected dialectal features. Perceptual and Motor Skills, 57, 71-78.

Bracken, B. A. (1986). Bracken Concept Development Program. San Antonio, TX: The Psychological Corporation.

Craig, H. K. (1995). Pragmatic impairments. In P. Fletcher \& B. MacWhinney (Eds.), Handbook of child language (pp. 623-640). Oxford, U.K.: Blackwell.

Craig, H. K., Thompson, C. A., Washington, J. A., \& Potter, S. L. (2003). Phonological features of child African American English. Journal of Speech, Language, and Hearing Research, 46, 623-635.

Craig, H. K., \& Washington, J. A. (1994). The complex syntax skills of poor, urban, African American preschoolers at school entry. Language, Speech, and Hearing Services in Schools, 25, 181-190.

Craig, H. K., \& Washington, J. A. (1995). African American English and linguistic complexity in preschool discourse: A second look. Language, Speech, and Hearing Services in Schools, 26, 87-93.

Craig, H. K., \& Washington, J. A. (2002). Oral language expectations for African American preschoolers and kindergartners. American Journal of Speech-Language Pathology, 11, 59-70

Craig, H. K., \& Washington, J. A. (in press). Language variation and literacy learning. In K. Appel, B. Ehren, E. Silliman, \& C. A. Stone (Eds.), Handbook of language and literacy development and disorders. New York: Guilford Press.

Craig, H. K., Washington, J. A., \& Thompson-Porter, C. (1998). Average c-unit lengths in the discourse of African American children from low income, urban homes. Journal of Speech, Language, and Hearing Research, 41, $433-444$

Donahue, P. L., Finnegan, F. J., Lutkus, A. D., Allen, N. L., \& Campbell, J. R. (2001). The nation's report card: Fourth-grade reading 2000 (NCES 2001-499). Washington, DC: U.S. Department of Education, Office of Educational Research and Improvement, National Center for Education Statistics.

Dunn, L., \& Dunn, L. (1997). Peabody Picture Vocabulary Test-Third Edition. Circle Pines, MN: American Guidance Service.
Fishman, J. A. (1991). Reversing language shift: Theoretical and empirical foundations of assistance to threatened languages. New York: Multilingual Matters.

Hester, E. (1996). Narratives of young African American children. In A. Kamhi, K. Pollock, \& J. Harris (Eds.), Communication development and disorders in African American children (pp. 227-245). Baltimore: Paul H. Brookes.

Hollingshead, A. B. (1975). Four Factor Index of Social Status. New Haven, CT: Yale University, Department of Sociology.

Hoover, H. D., Dunbar, S. B., \& Frisbie, D. A. (2001). Iowa Tests of Basic Skills. Chicago: Riverside.

Isaacs, G. J. (1996). Persistence of non-standard dialect in school-age children. Journal of Speech and Hearing Research, 39, 434-441.

Kaufman, A., \& Kaufman, N. (1983). Kaufman Assessment Battery for Children. Circle Pines, MN: American Guidance Service.

Labov, W., Baker, B., Bullock, S., Ross, L., \& Brown, M. (1998). A graphemic phonemic analysis of the reading errors of inner city children. Unpublished manuscript. Retrieved from http://www.ling.upenn.edu/ labov/Papers/ GAREC

MacWhinney, B. (1994). The CHILDES Project: Tools for Analyzing Talk (2nd ed.). Pittsburgh, PA: Carnegie Mellon University.

Metropolitan Achievement Tests (7th ed.). (1993). San Antonio, TX: Harcourt Brace.

Michigan Educational Assessment Program, State Summary Essential Skills Reading Grade 4. (19992001). Lansing, MI: State of Michigan.

Ninio, A., \& Snow, C. E. (1999). The development of pragmatics: Learning to use language appropriately. In W. C. Ritchie \& T. K. Bhatia (Eds.), Handbook of child language acquisition (pp. 347-383). San Diego, CA: Academic Press.

Ratusnik, D. L., \& Koenigsknecht, R. A. (1976). Influence of age on Black preschoolers' nonstandard performance of certain phonological and grammatical forms. Perceptual and Motor Skills, 42, 199-206.

Seymour, H. N., Bland-Stewart, L., \& Green, L. J. (1998). Difference versus deficit in child African American English. Language, Speech, and Hearing Services in Schools, 29, 96-108.

Shriberg, L. D. (1993). Four new speech and prosody-voice measures for genetics research and other studies in developmental phonological disorders. Journal of Speech and Hearing Research, 36, 105-140.

Shriberg, L. D., Austin, D., Lewis, B. A., McSweeny, J. L., \& Wilson, D. L. (1997). The percentage of consonants correct (PCC) metric: Extensions and reliability data. Journal of Speech, Language, and Hearing Research, 40, $708-722$.

Smitherman, G. (1998). Word from the hood: The lexicon of African-American Vernacular English. In S. S. Mufwene, J. R. Rickford, G. Bailey, \& J. Baugh (Eds.), African American English: Structure, history, and use (pp. 203-225). London: Routledge. 
Taylor, O. L., Payne, K. T., \& Anderson, N. B. (1987). Distinguishing between communication disorders and communication differences. Seminars in Speech and Language, 8, 415-427.

TerraNova CTBS. (1997). Monterey, CA: CTB/McGraw-Hill.

Thompson, C. A., Craig, H. K., \& Washington, J. A. (in press). Variable production of African American English across oracy and literacy contexts. Language, Speech, and Hearing Services in Schools.

Washington, J. A., \& Craig, H. K. (1994). Dialectal forms during discourse of urban, African American preschoolers living in poverty. Journal of Speech and Hearing Research, $37,816-823$

Washington, J. A., \& Craig, H. K. (1998). Socioeconomic status and gender influences on children's dialectal variations. Journal of Speech, Language, and Hearing Research, 41, 618-626.

Washington, J. A., \& Craig, H. K. (2002). Morphosyntactic forms of African American English used by young children and their caregivers. Applied Psycholinguistics, 23, 209-231.
Washington, J. A., Craig, H. K., \& Kushmaul, A. (1998). Variable use of African American English across two language sampling contexts. Journal of Speech, Language, and Hearing Research , 41, 1115-1124.

Wolfram, W. (1994). The phonology of a sociocultural variety: The case of African American Vernacular English. In J. Bernthal \& N. Bankston (Eds.), Child phonology: Characteristics, assessment and intervention with special populations (pp. 227-244). New York: Thieme.

Wolfram, W., \& Christian, D. (1989). Dialects and education: Issues and answers. Englewood Cliffs, NJ: Prentice Hall/Regents.

Received March 27, 2003

Accepted August 31, 2003

DOI: $10.1044 / 1092-4388(2004 / 036)$

Contact author: Holly K. Craig, PhD, University Center for the Development of Language and Literacy, University of Michigan, 1111 E. Catherine Street, Ann Arbor, MI 481092054.E-mail: hkc@umich.edu

Appendix A (p. 1 of 2). Morphosyntactic and phonological types of child AAE with examples. Asterisks denote the features that occurred in combinations.

\begin{tabular}{|c|c|c|}
\hline Morphosyntactic definitions & & Examples \\
\hline $\begin{array}{l}\text { Ain't } \\
\text { Ain't used as a negative auxiliary in have+not, do+not, } \\
\text { are+not, and is+not constructions }\end{array}$ & AIN & "you ain't know that?" \\
\hline $\begin{array}{l}\text { Appositive pronoun } \\
\text { Both a pronoun and a noun, or two pronouns, used to } \\
\text { signify the same referent }\end{array}$ & PRO & "and the other people they wasn't" \\
\hline $\begin{array}{l}\text { Completive done } \\
\text { Done is used to emphasize a recently completed action }\end{array}$ & DON & "done set the fire" \\
\hline $\begin{array}{l}\text { Double marking } \\
\text { Multiple agreement markers for regular nouns and verbs, } \\
\text { and hypercorrection of irregulars }\end{array}$ & DMK & $\begin{array}{l}\text { "he tries to kill } \text { him" } \\
\text { "they are taking the poor hitted boy to a hospital" }\end{array}$ \\
\hline $\begin{array}{l}\text { Double copula/auxiliary/modal } \\
\text { Two modal auxiliary forms are used in a single clause }\end{array}$ & MOD & $\begin{array}{l}\text { "once there was a turtle who chattered so much that she } \\
\text { should had no friends" }\end{array}$ \\
\hline $\begin{array}{l}\text { Existential it } \\
\qquad I t \text { is used in place of there to indicate the existence of a } \\
\text { referent without adding meaning }\end{array}$ & EIT & "I think it's a girl or a boy is yelling" \\
\hline $\begin{array}{l}\text { Fitna/sposeta/bouta } \\
\text { Abbreviated forms coding imminent action }\end{array}$ & FSB & $\begin{array}{l}\text { "he fitna be ten" } \\
\text { "he bouta fall" }\end{array}$ \\
\hline $\begin{array}{l}\text { Preterite had } \\
\text { Had appears before simple past verbs }\end{array}$ & HAD & $\begin{array}{l}\text { "he flew with a strong stick in his claws while the turtle had } \\
\text { held the stick fast in her mouth" }\end{array}$ \\
\hline $\begin{array}{l}\text { Indefinite article } \\
\qquad A \text { is used regardless of the vowel context }\end{array}$ & ART & $\begin{array}{l}\text { "one day she met a eagle traveling to a far-away lands } \\
\text { across the sea" }\end{array}$ \\
\hline $\begin{array}{l}\text { Invariant be } \\
\text { Infinitival be coding habitual actions or states }\end{array}$ & IBE & "and they be cold" \\
\hline $\begin{array}{l}\text { Multiple negation } \\
\text { Two or more negatives used in a clause }\end{array}$ & NEG & "it not raining no more" \\
\hline $\begin{array}{l}\text { Regularized reflexive pronoun } \\
\text { Hisself, theyself, theirselves replace reflexive pronouns }\end{array}$ & REF & "bouta fall and trying to hold hisself back up. \\
\hline
\end{tabular}


Appendix A (p. 2 of 2). Morphosyntactic and phonological types of child AAE with examples. Asterisks denote the features that occurred in combinations.

Morphosyntactic definitions

Remote past been

Been coding action in the remote past

*Subject-verb agreement

Subjects and verbs differ in marking of number

Undifferentiated pronoun case

Pronoun cases used interchangeably

Zero article

Articles are variably included

Zero copula/auxiliary

Copula and auxiliary forms of the verb to be are variably included

Zero -ing

Present progressive -ing is variably included

*Zero modal auxiliary

Will, can, do, and have are variably included as modal

auxiliaries

*Zero past tense

-ed markers are variably included on regular past verbs

and present forms of irregulars are used

*Zero plural -s is variably included to mark number

*Zero possessive

Possession coded by word order so $-\mathrm{s}$ is deleted or the case of possessive pronouns is changed

Zero preposition

Prepositions are variably included

Zero to

Infinitival to is variably included

Examples

BEN

SVA

UPC

ZAR

$\mathrm{COP}$

ING

AUX

PST

ZPL

POS

ZPR

ZTO
"I been knew how to swim"

"Our cat Mimi like_to sit on the roof"

"her fell"

"this cake is (the) best present of all"

"but she always comes down when it (is) time to eat"

"then you'(II) have to wear the brown ones instead"

"It was go(ing) to be a good birthday"

"he might_ been in the car"

"as soon as she open(ed) her moth, she fall straight into the ocean below"

"Father went out to buy some pretty flower_"

"The boy' ( $\underline{s})$ grandmother showed him how to put worms on the hook so they would not come off"

"she sits and looks (at) birds"

"that man right there getting ready _ slip on his one foot"

Phonological Definitions

Examples

*Postvocalic consonant reduction

Deletions of consonant singles following vowels

" $g$ " dropping

Substitutions of $/ \mathrm{n} /$ for $/ \mathrm{n} /$ in final word positions

Substitutions for $/ \theta /$ and $/ \delta /$

$/ \mathrm{t} /$ and $/ \mathrm{d} /$ substitute for $/ \theta /$ and $/ \partial /$ in prevocalic positions, /f, t/ and / $/ \mathrm{s}$ substitute for $/ \theta /$ and $/ \partial /$ in intervocalic positions, and in postrocalic positions

*Consonant cluster reduction

Deletion of phonemes from consonant clusters

Consonant cluster movement

Reversal of phonemes within a cluster, with or without consonant reduplication

Syllable deletion

Reduction of an (unstressed) syllable in a multisyllabic word

Syllable addition

Addition of a syllable to a word, usually as a hypercorrection

Monophthongization of diphthongs

Neutralization of diphthong

\begin{tabular}{|c|c|}
\hline PCR & $\begin{array}{l}\text { "mouth" } \\
/ \text { mav/ for } / \text { mav } \theta /\end{array}$ \\
\hline G & $\begin{array}{l}\text { "waiting" } \\
\text { /wetin/ for /wetın/ }\end{array}$ \\
\hline STH & 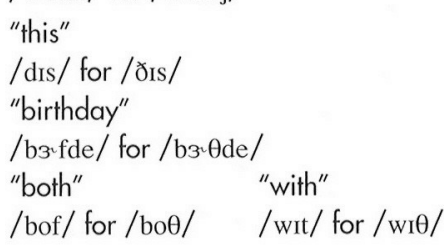 \\
\hline CCR & $\begin{array}{l}\text { "world" } \\
\text { /w31/ for /w3ld/ }\end{array}$ \\
\hline CCM & $\begin{array}{l}\text { "escape" } \\
\text { /Ekskep/ for / Eskep/ }\end{array}$ \\
\hline SDL & $\begin{array}{l}\text { "became" } \\
\text { /kem/ for / bikem/ }\end{array}$ \\
\hline SAD & $\begin{array}{l}\text { "forests" } \\
\text { /foristsiz/ for / forists/ }\end{array}$ \\
\hline VOW & $\begin{array}{l}\text { "our" } \\
\text { /ar/ for / aur/ }\end{array}$ \\
\hline
\end{tabular}

